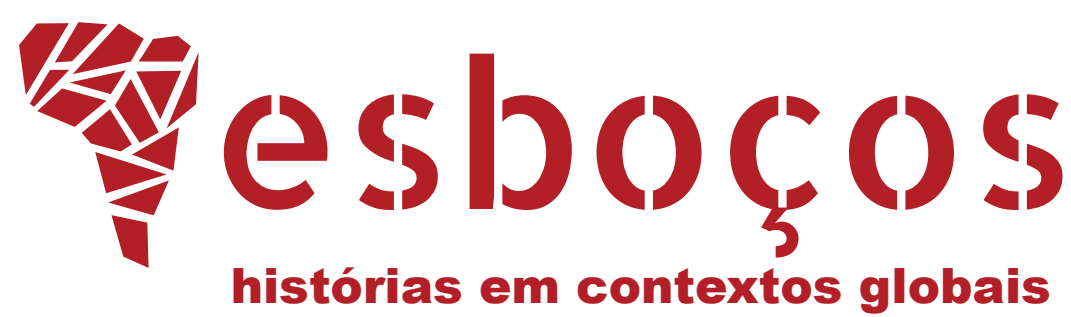

\title{
DA RADICAL À RADICADA: \\ ALTERIDADES ENTRE FRANCESES \\ E ESCRAVOS NO RIO DE JANEIRO \\ OITOCENTISTA
}

From Radical to Settled in: Forms of Otherness between French and Slaves in $19^{\text {th }}$ Century Rio de Janeiro 


\title{
RESUMO
}

A cultura liberal francesa do século XIX estimulou uma série de identidades mobilizadas por estrangeiros no Brasil. Para essa cultura, a persistente escravidão brasileira foi tema incontornável. Se viajantes franceses mobilizaram uma alteridade radical em contraposição tanto à escravidão como a brasileiros e africanos escravizados, franceses que buscaram se radicar no Brasil modularam outras formas de alteridade. Mediante análise de relatos de viagens e alforrias, este artigo explicita os significados relacionais de liberdade e as alteridades em movimento emuladas em redes de sociabilidade que, notadamente no Rio de Janeiro, uniram viajantes, agentes consulares, comerciantes e escravos. $O$ artigo demonstra em que medida estrangeiros radicados no Rio de Janeiro mobilizaram um vocabulário de distinções sociais e alteridades diferente daquele mobilizado por viajantes em seus relatos.

\section{PALAVRAS-CHAVE}

Escravidão. Condição estrangeira. Culturas liberais.

\begin{abstract}
French liberal culture in $19^{\text {th }}$ Century provided identities for foreigners in Brazil. Within this culture, persistent Brazilian slavery was an unavoidable subject. While French travellers emulated a radical otherness in contrast to both slavery and enslaved Africans, French who sought to establish themselves in Brazil ended up adhering to other kinds of otherness and identities. This essay highlights the relational meanings of freedom and the identities in the move which had been emulated in social networks that united travellers, consular officials and slaves in Brazil, mostly in Rio de Janeiro, by analysing travel accounts and manumission letters. It shows how settled foreigners used a vocabulary regarding social distinction and otherness which was different from the one used by travellers in their accounts.
\end{abstract}

\section{KEYWORDS}

Slavery. Foreign condition. Liberal cultures. 
m 1850, o outrora cônsul francês na Bahia, Francis de Castelnau, iniciava publicações referentes à segunda expedição que realizara nas Américas. As diferenciações entre os povos que encontrara, dentre as quais as que designou "condições do trabalho", condicionaram seu itinerário e a forma mediante a qual discriminou as regiões que o compuseram, tal como recapitulado em seu relato:

Embarcados, no Pará, em um navio a vapor que o governo brasileiro tinha colocado à minha disposição, com a benevolência a que ele me havia acostumado durante todo o curso de minhas viagens, dirigimo-nos a Caiena, onde o Sr. Deville ficou doente. Quanto a mim, tendo sido encarregado, por nosso governo, de estudar as condições diversas do trabalho nas colônias livres e de escravos, visitei o Suriname e Demerary, para me dirigir, em seguida, a Barbados, Santa Lúcia e à Martinica, onde passei algum tempo; depois, percorri rapidamente as pequenas Antilhas, até São Tomás, de onde o navio a vapor inglês me conduziu à Europa (CASTELNAU, 1850, p. 28-29, grifo nosso, tradução nossa). ${ }^{1}$

Liberdade e escravidão foram objetos de estudo para Castelnau, mas também categorias usadas para reiterar uma visão de mundo. É o que sugere sua menção à passagem pela ilha de Goreia. Nela, o francês expressa tanto seu apreço pela liberdade como uma distinção em relação ao "negro", independentemente da posição que este viesse a ocupar em eixo no qual, segundo Castelnau (1850, p. 44-45, grifo nosso, tradução nossa), ao conectar a África e as Américas, ele conectaria, também, "liberdade" e "escravidão":

Seria impossível descrever a alegria que senti ao pisar, pela primeira vez, no continente africano, onde tudo era tão novo para mim. Tendo estudado, durante longos anos, a raça africana transportada para as colônias da América, sempre tinha desejado ardentemente vê-la em seu próprio país, livre e independente; mas confesso que essa experiência só fez confirmar as ideias que eu tinha formado sobre o pequeno desenvolvimento intelectual dessa variedade da espécie humana. Aqui eu a encontrei, tal como na América, embrutecida pela bebida e pelas mais absurdas superstições; cômica em todos os seus movimentos, ela lembra sem cessar o macaco. O fato é que, livre na África ou escravo no Novo Mundo, o negro é sempre preguiçoso, depravado, ladrão e mentiroso; e a extrema facilidade com a qual se submete à escravidão é a prova da ausência, nele, de uma das mais nobres faculdades da alma humana. Reduzido ao cativeiro, o negro engorda; o índio da América se deixa morrer. ${ }^{2}$

\footnotetext{
${ }^{1}$ Tradução realizada com base na edição de 1850 e na tradução editada por Maria Elizabeth C. de Mello (2015, p. 34).

${ }^{2}$ Tradução realizada com base na edição de 1850 e na tradução editada por Maria Elizabeth C. de Mello (2015, p. 37).
} 
Não é surpreendente que esse viajante tenha sido apropriado como exemplo de "olhar francês". ${ }^{3}$ A liberdade que desejou para o "Outro" é a que reafirmou para si. Castelnau escrevia por meio de símbolos de uma cultura liberal que, embora de lógica universalista, teve centros específicos, dentre os quais a França, onde, muitas vezes, a própria identidade francesa foi liberal e universalista.

Toda identidade, no entanto, possui fronteiras. Que desafios uma identidade francesa encontraria nas ações daqueles que, porventura, deixassem a pátria francesa, tanto em viagens como no intuito de se enraizar em outro território? De que modo um país como o Brasil, com suas próprias lógicas de relações entre escravidão e colonialismo, poderia se apresentar a egressos da França, no complexo cenário de eixos atlânticos de escravidão e liberdade?

Abordando o problema de um "olhar francês" referente ao Brasil, este ensaio demonstra em que medida esse "olhar" se explica menos por sua origem e mais pela natureza de seus deslocamentos. Mediante análises de relatos de viajantes que estiveram no Brasil e de alforrias registradas em cartório por franceses estabelecidos em território brasileiro, demonstra-se em que medida o Brasil ofereceu à França ao menos duas possibilidades de alteridade. De um lado, uma alteridade radical, por meio da qual uma identidade francesa emulada enquanto continuidade de uma cultura liberal poderia se afirmar perante a permanência da escravidão no Brasil, distanciando-se de contradições inerentes a uma identidade liberal. De outro lado, uma alteridade que já se impunha, em circuitos do Estado francês, desde séculos anteriores - a radicada nas Américas, por intermédio da qual os que se enraizavam após um deslocamento atlântico se rendiam a formas de vida na qual o trabalho de cativos era condição essencial.

Para tanto, o ensaio se desdobra em três seções. Primeiramente, discute-se a inserção francesa em um quadro global de culturas liberais na passagem do século XVIII para o século XIX. Nesse quadro, a escravidão, notadamente quando vinculada ao colonialismo, foi problema incontornável de esfera pública. Em seguida, analisam-se modulações de alteridades tal como registradas por viajantes, reiterando-se a hipótese segundo a qual a condição viajante contribuiu para a manutenção de uma "alteridade radical", por vezes com pressupostos racialistas. Finalmente, analisam-se alforrias registradas em cartório, no intuito de averiguar em que medida a condição radicada no Brasil modulou alteridades diferentes daquelas emuladas em relatos de viagem, notadamente mediante a menção à cor enquanto "fator de identificação e classificação social, facilmente associado ao estatuto jurídico e usado de maneira ambígua para afastar ou aproximar alguém da escravidão ou do seu passado em cativeiro" (PINHEIRO, 2018, p. 44).

\section{MOVIMENTOS E CONEXÕES GLOBAIS, OU OS LIMITES DE UMA CULTURA LIBERAL}

Após 1789, muitos franceses encontrariam na palavra "liberdade" um alicerce de identidade. Instaurava-se no país uma "cultura liberal", ainda que "relativamente coerente" sobretudo como "cultura de oposição" (ROSANVALLON, 1985, p. 25) ao

\footnotetext{
${ }^{3}$ Expressão usada por Maria Elizabeth C. de Mello (2015, p. 19).
} 
Antigo Regime. ${ }^{4}$ Por meio dela, identificar-se francês pressuporia encarnar valores universalistas e crer na máxima monumentalizada no Panthéon de Paris, em estátua dedicada à memória da Convenção: "Vivre libre ou mourir". ${ }^{5}$

No entanto, essa cultura se deparava com heranças que diziam tanto sobre o Ocidente como os "princípios de 1789", para usar a expressão de Pierre Rosanvallon (1985, p. 25). Entre elas, a escravidão. A instituição que o jacobinismo acreditou ser capaz de guilhotinar, mas cujo restabelecimento por Napoleão Bonaparte, em 1802, é tão emblemático quanto a coroação do militar pelas mãos do papa, anos mais tarde, era respaldada até mesmo pelo Novo Testamento, no qual "distinções temporais não tinham muita importância" e, em função disso, "se um homem era chamado a ser escravo, não devia tentar se tornar livre" (DAVIS, 2001, p. 105). Não à toa, quando da declaração de guerra à França revolucionária por parte da Inglaterra, franceses que viviam às custas do trabalho de seus escravos reconheceram nos britânicos seus salvadores (BLACKBURN, 2011, p. 149).

De fato, após a primeira tentativa de abolição, a escravidão permaneceu na arena política francesa. Isso decorreu principalmente de "uma conexão que as potências europeias tentariam manter debaixo do pano no século e meio seguinte: a relação entre escravidão e colonialismo", exacerbada em função da Revolução do Haiti (COOPER et al., 2005, p. 55). Apesar da instauração de uma república em 1804, permaneceu o "sonho" de não apenas recuperar o domínio sobre a antiga colônia, mas também, para muitos, o desejo de lá reinstaurar a escravidão (BRIÈRE, 2008, p. 17-19). O supracitado restabelecimento da escravidão por parte de Napoleão tem igualmente seu significado elucidado quando se recorda que já "sob o Consulado, a esperança de uma paz com a Inglaterra levou Bonaparte a reatar com especulações coloniais do Antigo Regime em eixo triangular religando portos atlânticos, as Antilhas e a Louisiana" (GRENOUILLEAU, 2017, p. 32). A Restauração, por sua vez, também rearticulou colonialismo e escravidão: entre 1814 e 1831, "cerca de 125.000 novos escravos foram introduzidos no Caribe por negociantes franceses", em conjuntura de preços que tornou colonos ávidos por comprar escravos, "se possível a crédito, e encorajou mercadores a suprir essa demanda" (BLACKBURN, 2011, p. 476). A abolição de 1848, enfim, não encerrou o dilema. Se uma nova revolução criou a efeméride que deu às relações entre liberalismo e democracia "a ilusão de sua resolução" (ROSANVALLON, 1985, p. 14), os desafios em uma conjuntura atlântica de emancipação permaneceram muitos. Essas tensões extrapolavam a territorialidade francesa. O próprio império britânico, a despeito de sua projeção em esfera pública no combate ao tráfico de escravizados (BLACKBURN, 2011), também enfrentava desafios em suas colônias, nas quais "a transição da sociedade escravista para uma sociedade livre acabaria por expor as contradições da ideologia liberal" (HOLT, 2005, p. 104). Escravidão e abolição permaneceram, portanto, dilemas para culturas liberais do século XIX.

\footnotetext{
${ }^{4}$ As citações de estudos originalmente em francês e em inglês são traduções livres.

${ }^{5}$ Ideais de liberdade não foram monopólio francês. Porém, termos caros à cultura política francesa retiveram "associações com valores morais e humanos de ordem geral", expressando tanto o "nacionalismo e expansionismo franceses" como "a crença em que a tradição nacional francesa consubstanciava e representava valores morais e outros, bem como realizações válidas para a humanidade como um todo" (ELIAS, 1997, p. 130).
} 
Decorrente de tal quadro foi a consolidação de novas formas de racismo e racialismo, ${ }^{6}$ em reação à lógica de 1789 . O "universalismo humano implícito na crítica antiescravidão foi desafiado por uma doutrina racial mais geral, e mesmo "científica", que supostamente justificava a escravidão" (BLACKBURN, 2011, p. 154). Logo, "por mais paradoxal que possa parecer, o nascimento, o desenvolvimento e o êxito do abolicionismo coincidem com o reforço e o apogeu de um racismo que se torna, no século XIX, simultaneamente mais popular e mais 'científico"' (GRENOUILLEAU, 2017, p. 21). Tratava-se de preservar privilégios, pois, como apontou Claude Meillassoux (2002, p. 9), "o racismo é apenas um avatar do preconceito aristocrático de classe", o que explica manifestações como a supracitada formulação de Castelnau.

É nesse quadro global de culturas liberais que se tornam elucidativos os movimentos e conexões por meio dos quais "liberdade" e "escravidão" foram reinventadas ao longo do século XIX. Um olhar sobre franceses que se deslocaram durante esse século permite reconhecer nos movimentos de suas alteridades a condição tanto para a exaltação da liberdade como para a persistência da escravização. Com efeito, uma relação de alteridade é "o meio seguro de manter a distância social, que é a condição da escravidão" (MEILLASSOUX, 1995, p. 59), pois "nunca se escraviza um semelhante" (PÉTRÉ-GRENOUILLEAU, 2009, p. 40). Conceitos de liberdade, por sua vez, têm seu potencial elucidado mediante a produção de diferenças em conflitos, haja vista que sua importância "não está simplesmente no poder intelectual intrínseco destes conceitos, mas em sua vinculação com uma história do poderio europeu que se estendeu sobre boa parte do globo" (COOPER et al., 2005, p. 53).

Nesse quadro, a condição viajante se destaca. É como se a equação proposta por Claude Meillassoux (1995), segundo a qual a condição de "estrangeiro absoluto" é um dos critérios por meio dos quais se torna possível apreender antropologicamente o estado de escravo, ${ }^{7}$ pudesse se aplicar também ao viajante, ainda que em outra direção. Assim como o escravizado, é também o viajante um estrangeiro absoluto. Porém, ele pode se colocar acima da escravidão, denunciando aqueles que a tornaram instituição viva. Esteve em jogo, enfim, a distinção inerente à vida social, da qual o viajante parece se afastar, em função de sua ilusória condição de desenraizado absoluto, emulada por meio do tópos da "sensação de não estar de todo" (SÜSSEKIND, 1990, p. 21).

É nesse ponto que o radicado se diferencia do viajante, sobretudo em um território como o brasileiro. Se é verdade que, no tocante à trajetória de uma cultura liberal, houve descompassos entre a França metropolitana e os circuitos coloniais franceses, ${ }^{8}$ é plausível imaginar descompassos ainda mais fortes em relação a um

\footnotetext{
"Uso o termo "racialismo" em diferenciação ao termo "racismo" com base nas formulações de Tzvetan Todorov (1989, p. 134), para quem o racismo seria "um comportamento antigo, e de extensão provavelmente universal", ao passo que o racialismo seria "um movimento de ideias nascido na Europa ocidental, cujo grande período vai do meio do século XVIII ao meio do século XX".

${ }^{7}$ É nesse sentido que este ensaio se vale com mais frequência do termo "escravos", em filiação à possibilidade de identificar o "âmbito geral de determinação que modela o seu estado comum, em relação ao qual se definem, em cada sociedade escravagista, as condições individuais, diversas e mutáveis de cada um deles" (MEILLASSOUX, 1995, p. 11, grifos do autor).

${ }^{8}$ No tocante à revolução de 1789 , é mesmo verossímil a hipótese segundo a qual "realidades coloniais permaneceriam obscuras para a opinião pública da época" (PIOLLET; PIQUIONNE; ROUX, 2002, p. 25). O descompasso se manteve sobretudo até 1830. Como ressaltou Letícia G. Canelas (2018, p. 47), ao longo da Restauração, a vontade senhorial e atos pessoais predominaram em colônias francesas mediante a distinção entre as operações de "manumissão" e "alforria legal".
} 
Estado como o brasileiro. Foi nessa confluência que o Brasil oitocentista ofereceu, a franceses que se deslocaram, a possibilidade de novas alteridades.

\section{VIAJANTES FRANCESES NO BRASIL ESCRAVISTA, OU A MANUTENÇÃO DE UMA ALTERIDADE RADICAL}

A construção do Estado brasileiro se inseriu nos quadros da escravidão e da abolição em contexto atlântico, tanto mediante negociações diplomáticas com a Inglaterra como por meio da "conivência do governo imperial com a ilegalidade" no tocante ao tráfico que levou ao território brasileiro "cerca de 800 mil africanos entre 1830 e 1856", segundo Beatriz Mamigonian (2017, p. 20). As histórias desses africanos estiveram em meio à "confluência de processos globais" (MAMIGONIAN 2017 , p. 27), assim como as de viajantes de diversos países, com seus interesses individuais (SÜSSEKIND, 1990, p. 114) e posicionamentos diante da escravidão (ROSSATO, 2007, p. 192).

Da França partiu quantidade expressiva de viajantes rumo ao Brasil (POTELET, 1993; KURY, 2001; LEITE, 1996; ROSSATO, 2007). ${ }^{9}$ Seus posicionamentos perante a escravidão foram variados, mas é possível identificar padrões. Muitos sublinharam "o caráter de uma economia que, em todos os seus domínios, baseia-se na mão de obra servil" (POTELET, 1993, p. 142). Outro padrão foi a alteridade manifestada em relação ao "africano", principalmente mediante generalizações. Apesar de uma maior interação francesa com o interior da África na primeira metade do século XIX (GRENOUILLEAU, 2017), distinções originárias da África se diluíam para muitos viajantes, tanto em decorrência da inserção dos cativos nas Américas - uma vez que "foi nas fazendas e cidades americanas que milhões de homens e mulheres, oriundos de diversas sociedades e tradições culturais, foram levados a se fazerem africanos" (GÓES, 2003, p. 206) -, como em função da escolha de viajantes que conceberam um exotismo brasileiro como extensão de um exotismo africano (POTELET, 1993, p. 143; ARAUJO, 2017, p. 107).

Esse foi o caso do oficial da Marinha Louis de Freycinet (1779-1842). Em expedição que o levou ao Rio de Janeiro, Freycinet seguia instruções para inventariar aspectos fisiológicos e culturais dos povos encontrados. ${ }^{10} \mathrm{Em}$ seu relato, os "negros escravos" do Rio de Janeiro foram descritos tal como em uma taxonomia de espécies:

A espécie de negros escravos que mais se encontra no Rio de Janeiro provém de Angola e de Benguela. [...] Os angolanos propriamente ditos são violentos; eminentemente preguiçosos, trabalham com grande desleixo; são os mais lentos de todos os

\footnotetext{
${ }^{9}$ O relato de viagem "alia domínios e gêneros diferentes" (GANNIER, 2001, p. 9). Em função disso, a escolha dos textos para este ensaio seguiu dois critérios sociológicos relacionados à autoria desses materiais. Primeiramente, elencaram-se relatos de viajantes que se vincularam a agentes consulares, também elencados em função do registro de alforrias. Em seguida, elencaram-se relatos de viajantes que buscaram se distinguir de outros franceses situados no Rio de Janeiro. Não se trata, portanto, de reiterar a categoria de um "olhar francês" em relatos, mas de, justamente, explicitar variações internas no corpus de relatos de viagem franceses.

${ }^{10}$ As instruções encontram-se arquivadas no Service historique de la Défense, em Vincennes (França), no códice 999 da sub-série BB4.
} 
negros. Eles aprendem o português com muita facilidade: essa aptidão natural é comum aos vindos de Benguela. Observamos que esses últimos são mais propensos que os outros escravos a fugirem da casa de seus senhores. Em geral bem-dispostos, espertos, engraçados, sem rancor, os Cabindas são também, no entanto, muito preguiçosos, pois, em seu país, são quase sempre as mulheres que se encarregam dos trabalhos pesados; todavia, se comprados com menos de 20 anos e bem-orientados, podem ser utilizados em todas as tarefas, pois são extremamente habilidosos. Os negros do Congo têm qualidades e vícios mais ou menos semelhantes: há poucos deles que têm estatura elevada. Os indivíduos dessa nação - ou melhor, dessas nações, pois há infinitas subdivisões tatuam desenhos bizarros em diversas partes do corpo, mas raramente tatuam o rosto. Os negros de Moçambique são tidos como bons trabalhadores, sobretudo se empregados como marinheiros e barqueiros; porém, têm fama de serem excessivamente mentirosos (FREYCINET, 1825, p. 195-196). ${ }^{11}$

Aalteridade perante africanos não foi a única mobilizada por viajantes franceses no tocante à escravidão brasileira. Muitos se diferenciaram de outros franceses. Eles reconheceram um éthos em compatriotas radicados em terras brasileiras e refrataram, em relatos, disputas que vigiam em território francês. Para eles, franceses "instalados" no Brasil teriam se afastado de um ideal de civilização caro à identidade francesa. Foi assim que, como apontou a historiadora Claudia Santos (2013, p. 89), F. Dabadie denunciou "a passividade dos franceses face à prostituição de escravas; [e] os preconceitos de seus compatriotas contra os negros", pois ceder à escravidão seria, aos seus olhos, trair um "instinto" francês. A reação de Dabadie foi não apenas a de um quarante-huitard, mas também aquela promovida pelo Estado francês, que por meio do decreto de 27 de abril de 1848 proibia a posse de escravos por franceses, sob risco de perda da nacionalidade (SANTOS, 2013, p. 89, 114). Dabadie (1859, p. 8, grifo do autor), todavia, explicitou o potencial radical dessa identidade francesa baseada em ideal mais amplo, da qual "a pátria de Voltaire e Condorcet" seria exemplo:

\begin{abstract}
A escravidão, eis a chaga do Brasil, é esta sua vergonha, é este seu crime perante os olhos da civilização; vergonha e crime tão intensos, que todas as antigas colônias espanholas da América meridional finalmente reconheceram os direitos sagrados da humanidade e libertaram os negros. Os sofistas interessados em defender uma causa má, uma causa ímpia, ousam pretender, além do Oceano e mesmo em meio a nós, na pátria de Voltaire e Condorcet, que devemos entregar ao tempo o cuidado de preparar a abolição de uma propriedade imoral. Isso é um ultraje à razão, e temos dúvidas de que eles já tenham sentido um coração bater no peito.
\end{abstract}

\footnotetext{
11 Tradução livre baseada na edição de 1825 e na tradução editada por França (2013, p. 156-157).
} 
Adèle Toussaint-Samson (1826-1911) também emulou alteridades radicais, tanto em relação a compatriotas como em relação a brasileiros e a negros. A publicação Une parisienne au Brésil, referente à sua estada no país na década de 1850, apresenta críticas a franceses donos de escravos no Rio de Janeiro. Nela, Toussaint-Samson (2003, p. 85-86) narrou os hábitos de um casal que a acolhera, "parvenus em toda a força do termo", sublinhando que o homem desse casal "só abria a boca para falar de sua riqueza e de seus escravos". A repulsa perante compatriotas, todavia, não decorreu de empatia por brasileiros e pessoas escravizadas. Ao descrever a "raça brasileira", afirmou que "é ao comércio com os negros que se deve em parte a deterioração dessa raça" (TOUSSAINT-SAMSON, 2003, p. 85-86). Ao abordar a conivência do governo com a escravidão, Toussaint-Samson (2003, p. 99) sustentou que o imperador "precisava fechar os olhos ao tráfico de negros, pois apenas eles eram capazes de suportar os trabalhos de cultura sob aquele sol de fogo". A parisiense também registrou reservas perante a abolição, alertando que o "grande número de negros livres" seria "um grande ponto escuro no horizonte brasileiro [pois] seu número já ultrapassa o dos brancos", e registrando a esperança de que "o Brasil não tenha seu São Domingos" (TOUSSAINT-SAMSON, 2003, p. 102).

Outro exemplo de alteridade radical com inflexões racialistas foi a emulada pelo pintor François Auguste Biard. Esse francês apresentou o que Ana Lucia Araujo (2017, p. 26) identificou como "posição ambígua" em relação à escravidão. Em função de sua colaboração com a monarquia, o pintor "não tinha a intenção de oferecer sérios comentários críticos sobre a sociedade brasileira e suas elites", embora tenha produzido "representações satíricas da vida cotidiana brasileira e da escravidão, que às vezes também ridicularizavam os indivíduos de origem europeia" (ARAUJO, 2017, p. 140). A radicalidade da alteridade emulada pelo pintor evidencia-se pela equivalência entre a condição escrava e o termo "negro", explicitada em sua surpresa diante da presença de negros em comemoração do aniversário da independência do Brasil no Rio de Janeiro. Para Biard, segundo Araujo (2017, p. 128), eles estariam celebrando "a independência de um povo de quem eles eram escravos". O pintor corroborou, portanto, uma distinção chave no cenário atlântico, no qual "a escravidão do Novo Mundo codificou a pele 'negra' como uma característica escrava” (BLACKBURN, 2011, p. 19).

Em resumo, as alteridades registradas por esses franceses foram sintomáticas da condição viajante da qual eles usufruíram. A ausência de estabelecimento permitiu uma crítica enfática à escravidão, e mesmo a distinção perante demais franceses. No entanto, sendo o estabelecimento a decorrência de uma lógica de sociabilidades - a ponto de mesmo uma "anomia" indicar "um tipo específico de estrutura social, e não seu polo oposto num contínuo de fenômenos sociais" (ELIAS, 2000, p. 33) -, não surpreende que aquele que não dispusesse de condição fluida como a do viajante se estabelecesse, em terras brasileiras, por intermédio da escravidão. A alteridade radical se valia de a distinção de poder "não estar de todo", privilégio relacional da condição viajante perante a condição estrangeira, a qual, por sua vez, exige a introjeção de outras hierarquias sociais e, portanto, de uma alteridade radicada. 


\section{OS RADICADOS, OU O ESTABELECIMENTO DA CONDIÇÃO ESTRANGEIRA POR MEIO DA ESCRAVIDÃO}

Não à toa, foi um radicado que auxiliou muitos viajantes. Tanto Castelnau como Biard puderam circular em solo brasileiro por meio do auxílio de um mesmo compatriota: o cônsul Theodore Taunay (1797-1881). Castelnau o cita em seu relato, narrando a recepção realizada pelo cônsul (1850). Também Biard foi recebido no Rio de Janeiro por Taunay (SANTOS, 2013, p. 84), que, além disso, intermediou o contato do pintor com o cônsul francês no Pará (ARAUJO, 2017, p. 146). Porém, cartas de recomendação não foram as únicas que passaram pelas mãos de Taunay. Vestígios do auxílio a compatriotas são as cartas de alforria que o cônsul registrou em cartório.

Essas cartas remetem à complexidade das "práticas tendentes à liberdade", em função das quais alforrias e liberdades podem ser entendidas "como processo, e não como resultado" (SECRETO, 2011, p. 147). No tocante a essas práticas, o Brasil oitocentista apresentou especificidades, com modalidades de compra, ou outorga sob condições, as quais culminavam em situação "particularmente frágil", junto à "prática comum de compra da alforria mediante endividamento do libertando" (CHALHOUB, 2012, p. 248). Houve, em meio às distinções entre escravos e diferenciações regionais, "possibilidades diferenciadas de negociação" (REIS; SILVA, 1989, p. 20), em função de que "o ex-escravo baiano não se parece absolutamente ao alforriado de São Paulo" (MATTOSO, 1990, p. 199), o que fez de "cada manumissão, praticamente, um caso singular" (GONÇALVES, 2011, p. 20). Além disso, o século XIX apresentou suas próprias especificidades. Como ressaltou Andréa Lisly Gonçalves (2011, p. 172), "os primeiros setenta anos do século XIX se apresentam como um período privilegiado para apreensão das mudanças do significado da política de alforrias". De todo modo, é possível identificar tendências preponderantes, como no tocante ao Rio de Janeiro oitocentista (SANCHES, 2017). Isso se dá em função do número expressivo de registros de cartas de liberdade, muitos dos quais visavam "evitar contestação" (MATTOSO, 1990, p. 177). É nesse quadro que o papel de Taunay tem seu sentido elucidado. Ao registrar cartas de liberdade em cartório, o cônsul aderiu a significados locais da prática de alforrias, em seus vínculos com os eixos atlânticos que reconfiguraram "escravidão" e "liberdade" ao longo do século XIX.

Foi o retorno de Jean Croset à França, por exemplo, que levou Taunay a registrar, em 1853, a liberdade do africano Januário Cabindo. Quando do registro, o cônsul declarou que Januário tornava-se "forro, quando d'hoje em diante de sua plena liberdade como também o declara o Francês João Matheus Croset, a quem d'antes pertenceu, e estando a partir para a França, dá-Ihe sua Alforria". ${ }^{12}$ Esse tipo de registro situou o cônsul em um interstício de redes, cuja ambiguidade se manifestou em sua relação com a escravidão brasileira. Por um lado, Taunay representava em solo brasileiro o Estado que em 1848 exigira, como já sublinhado, o divórcio entre cidadania francesa e escravidão. Por outro lado, ao intermediar percursos transnacionais de compatriotas por meio do registro de cartas de liberdade, Taunay reiterou o padrão conservador da alforria no Brasil.

\footnotetext{
${ }^{12}$ Arquivo Nacional (Rio de Janeiro), BR RJANRIO 5E.0.LRG.87 - $2^{\circ}$ Ofício de Notas (RJ), Livro de registro geral $n^{\circ} 87$, f. $139 v$. Doravante as referências ocorrem mediante as abreviaturas "ANRJ", "Of. de Notas" e "LRG".
} 
O papel de Taunay enquanto intermediário não se restringiu ao caso de Januário. Em janeiro de 1848, o então "consul chanceller da legação de França no Brasil" registrara o "papel de liberdade" que dera ao "preto Mathias Crioulo da Bahia", que pertencera "ao finado francês Denis Devrand falecido no Rio de Janeiro". ${ }^{13} \mathrm{O}$ comprometimento com o registro da liberdade de Mathias provavelmente havia sido acordado entre conterrâneos quando da iminência da morte de Devrand. Mais eloquente foi, por sua vez, a relação que permitira a Taunay efetuar o registro da liberdade da crioula Maria. Ela era "filha da finada Perpétua de Nação Cabinda e de Sabino Moçambique", então "também falecido", tendo sido "ambos antigamente escravos do finado Conde de Gestas, ex-Consul Geral de França no Brasil", ${ }^{14}$ que recebera em sua propriedade na Tijuca o supracitado Freycinet.

Enviado ao Brasil pelo rei Luís XVIII, em missão concebida pelo então ministro de Assuntos Estrangeiros René de Chateaubriand, o conde Aymar de Gestas pôde comprar "numerosas ilhas na baía do Rio de Janeiro", além de propriedade na Tijuca, onde, por meio de plantações de café, recuperara a fortuna perdida ao longo dos turbulentos anos políticos franceses - processo no qual seus cerca de trinta escravos foram essenciais (GAIN, 1930, p. 61-62). O vínculo com a escravidão não impediu Freycinet de descrevê-lo de modo terno, em elogio ao compatriota, mobilizando, assim, uma identidade diferente daquela reiterada anos mais tarde por um francês como Dabadie. Para Freycinet (1825, p. 29-30), Gestas tinha "todas as inabaláveis e brilhantes qualidades que podem proporcionar a melhor educação, caráter e virtudes mais raros do que a sabedoria e os talentos", e a "fraternidade recíproca" evidenciada seria o resultado de "emoções análogas àquelas que sentiam os primeiros cristãos, nos tempos das perseguições, ou mesmo depois desta época deplorável, quando, longe do solo natal, um feliz acaso os fazia se reencontrarem".

É plausível imaginar que Freycinet teria tido acesso aos serviços de um cativo sob domínio de Gestas. Nesse caso, o oficial se enquadraria na condição reconhecida por llka Boaventura Leite (1996, p. 210-211) como contraditória, pois "os viajantes viveram também as condições de serem senhores de escravos, ou de utilizarem tal mão de obra, mesmo indiretamente, quando se tornavam hóspedes dos senhores". Todavia, essa condição não teria sido, em si, contraditória, mas sim a lógica de uma sociabilidade situada em território que exigiria outra modulação de alteridade. Franceses, enquanto senhores, auxiliaram-se no acesso a cativos. Evidência é o fato de que, quando da morte de Gestas, Perpétua e Sabino, os pais da supracitada Maria, encontraram-se vinculados a outro senhor, igualmente francês. É o que consta da alforria registrada por Taunay em 1852, na qual explicitase a condição dos pais de Maria, "cujos serviços a ocasião da morte do mesmo conde de Gestas em mil oitocentos e trinta e sete" foram transferidos "por tempo limitado ao francês Ambroise", que se encontrava "falecido igualmente" quando do registro da alforria. Foi por ter "nascido depois do contrato passado com o mesmo francês Ambroise" em relação a "serviços de seus Pai e Mãe" que Maria teve sua liberdade outorgada por Taunay em $1852 .{ }^{15}$ De modo semelhante, o falecimento do

\footnotetext{
${ }^{13}$ ANRJ, BR RJANRIO 5E.0.LRG.79 - 2० Of. de Notas (RJ), LRG n ${ }^{\circ} 79$, f.118.

${ }^{14}$ ANRJ, BR RJANRIO 5E.0.LRG.84 - $2^{\circ}$ Of. de Notas (RJ), LRG n ${ }^{\circ} 84$, f. $423 \mathrm{v}$.

${ }^{15}$ ANRJ, BR RJANRIO 5E.0.LRG.84 - 2 ${ }^{\circ}$ Of. de Notas (RJ), LRG n 84 , f. 424.
} 
conde de Sevy permitiu que o cônsul registrasse, em setembro de 1849, a liberdade de outro escravo, também nascido no Brasil. ${ }^{16}$

O registro da liberdade de Maria frisou o comprometimento entre conterrâneos que, no Brasil, se auxiliaram por meio da escravidão. No tocante a Taunay, como já afirmado, o ato de registrar as alforrias reiterou a prática em contexto brasileiro, tal como no caso das liberdades conferidas ao "preto Antonio de nação Mina" e ao "preto Paulo de nação Moçambique", registradas em 1853. ${ }^{17}$

Cabe ainda se indagar acerca do vínculo entre Taunay e esses escravos durante o período que se estendeu da morte ou viagem dos senhores até o registro das alforrias. No caso supracitado entre Mathias e Denis Devrand, há que se considerar que o senhor falecera meses antes da outorga da liberdade, ocorrida em dezembro de 1847 e registrada em janeiro de 1848. Sob que tipo de vínculo pessoal esteve Mathias subordinado ao cônsul? É plausível inferir que Taunay pôde usufruir de seus serviços, ou dos serviços de outros escravos pertencentes a demais conterrâneos. Esses serviços podem ter até sido conferidos a Castelnau, não só quando da recepção de sua expedição, mas em trabalhos científicos - inferência plausível, pois viajantes fizeram uso da mão de obra escrava (LEITE, 1996, p. 111). Talvez tenha estado sob domínio de Taunay o "negro" que Castelnau menciona em seu relato, o qual fora levado em excursões pelas "belas cenas da natureza" carioca, e que seguia a expedição conforme levava "um grande cesto sobre a cabeça", de modo que o viajante pudesse reunir coletas botânicas (CASTELNAU, 1850, p. 92).

Tornar-se senhor não foi privilégio apenas para franceses no corpo diplomático, não só pelo fato de que a posse de escravos não implicaria automaticamente posição privilegiada no Brasil oitocentista, ${ }^{18}$ mas também porque franceses que desempenhavam outras ocupações igualmente adquiriram cativos. A escravidão não foi um incômodo para muitos franceses estabelecidos no Brasil após $1814^{19}$ mediante a atividade que, para um philosophe como Voltaire ou adeptos da "teoria dos quatro estágios", ${ }^{20}$ seria o vetor da civilização e da união entre povos: o comércio - instituição que adeptos de uma ideologia liberal afirmaram ser a via pela qual libertos "deviam 'aperfeiçoar-se na civilização'” (HOLT, 2005, p. 123).

Esse parece ter sido o caso de Ignace Ratton, que, na década de 1840, destacava-se enquanto conselheiro da Companhia Brasileira dos Paquetes de Vapor, da seguradora Phenix Fluminense e do Banco Comercial do Rio de Janeiro (ALMANAK LAEMMERT, 1843, p. 175), além de ter pertencido à Comissão da Praça do Comércio (ALMANAK LAEMMERT, 1844, p. 230). Provavelmente o bom posicionamento no cenário comercial carioca favoreceu a disposição a libertar gratuita e incondicionalmente, no final da década de 1830, Raquel, Adelaide e Clarinda,

\footnotetext{
${ }^{16}$ ANRJ, BR RJANRIO 5E.0.LRG.81 - 2० Of. de Notas (RJ), LRG n 81, f. 189.

${ }^{17}$ ANRJ, BR RJANRIO 5E.0.LRG.85 - $2^{\circ}$ Of. de Notas (RJ), LRG n 85, f. 223v.

${ }^{18} \mathrm{~A}$ posse de escravos e mesmo $\mathrm{o}$ ato de alforriar não indicavam necessariamente um posicionamento social bem favorecido, tal como demonstrado no estudo de lan Read sobre Santos (2012).

${ }^{19} \mathrm{O}$ ano de 1814 foi uma ruptura no tocante às relações entre Brasil e França (LEITE, 1996, p. 64; POTELET, 1993, p. 14).

${ }^{20}$ Um campo de formulações reconhecido pela historiografia como "teoria dos quatro estágios" foi recorrente em fins do século XVIII e concebia a classificação de povos de acordo com a natureza de suas atividades de subsistência (KURY, 2001, p. 20).
} 
referindo-se a todas por meio do termo "pardinha", ${ }^{21}$ em menção à cor tributária da "demarcação das hierarquias sociais do Antigo Regime português" (PINHEIRO, 2018, p. 44). Elas eram filhas de escravas suas, sendo Adelaide filha de Úrsula, e Raquel e Clarinda filhas de Mafalda. Todavia, a concessão gratuita não ocorreu anos mais tarde: em 1848, Ratton libertou Manoel, filho de Úrsula, em função de uma moléstia nos olhos do cativo. A alforria foi concedida mediante pagamento feito pela mãe do escravo. ${ }^{22}$

Assim como Ratton, outros descendentes de famílias francesas inseridos no campo do comércio e das finanças também interagiram com a escravidão. $\mathrm{Na}$ década de 1840, C. Le Blon destacava-se na praça fluminense enquanto corretor de seguros (ALMANAK LAEMMERT, 1844, p. 238). Anos mais tarde, sua inserção continuava eficaz, a ponto de participar da reunião de seguradores particulares de riscos marítimos da Praça do Comércio (ALMANAK LAEMMERT, 1855, p. 362). O trabalho de Manoel provavelmente foi de grande valia ao bem-sucedido senhor, que em 1858 libertava gratuitamente o cativo "pardo", devido a "bons serviços". ${ }^{23}$ Também aderiu à escravidão Auguste Lehericy, francês nato que consta da edição referente ao ano de 1845 do Almanak Laemmert sob a rubrica de "negociante estrangeiro" (ALMANAK LAEMMERT, 1844, p. 234). Ao passo que muitos senhores se valiam de relações pessoais para conceder liberdade, Lehericy reiterou a via do mercado, e foi também mediante mercado que manteve sob sua influência o trabalho de alforriados. É o que indica a libertação da crioula Miquelina, mantida em condição de servir em vida, mas recebendo um salário de 10 mil réis por mês. ${ }^{24}$

Redes entre franceses ou descendentes de franceses também podiam auxiliar a aquisição de cativos. É o que se averigua no registro de um "escrito de liberdade conferido por Luis Francisco Delouche, ao pardo de nome Paulo", que ocorreu em dezembro de 1857. No registro, Delouche se apresenta como "senhor e possuidor dos serviços do pardo Paulo, conforme a compra que dos mesmos [fizera] a Carlos Duffau Panillac na qualidade de procurador de Julio Manoel Lopes Dias, pelo resto do tempo que faltava, para completar a idade de vinte annos". Esse registro evidencia também o caráter da manutenção de laços pessoais após a outorga da liberdade. Delouche sublinhou que, "como o dito pardo Paulo tenha completado a idade marcada", chegava então o momento de Ihe conferir "irrevogável liberdade" para que dela pudesse "gozar sem mais condição alguma, e como se livre nascesse, sem que a esta liberdade ninguém possa por obstáculos". Tendo-se em vista as possibilidades de revogação da alforria (MATTOSO, 1990, p. 180), sobretudo por ingratidão (PINHEIRO, 2018, p. 120), a menção ao caráter irrevogável denota uma posição em meio às práticas de produção de liberdade. Mais ilustrativo ainda é o fato de o próprio senhor prometer fazê-la "firme e valiosa por todo o tempo", frisando os laços pessoais no âmbito da emancipação. ${ }^{25}$

O que esse quadro mostra é o papel desempenhado pela condição estrangeira ${ }^{26}$ na produção de liberdade. Africanos e europeus, ao se enraizarem no

\footnotetext{
${ }^{21}$ ANRJ, BR RJANRIO 5E.0.LRG.71 - 2० Of. de Notas (RJ), LRG n 71, ff. 131-132.

${ }^{22}$ ANRJ, BR RJANRIO 5F.0.LRG.08 - $3^{\circ}$ Of. de Notas (RJ), LRG n08, f. 123.

${ }^{23}$ ANRJ, BR RJANRIO 5F.0.LRG.18 - 3० Of. de Notas (RJ), LRG n॰ 18, f. $91 \mathrm{v}$.

${ }^{24}$ ANRJ, BR RJANRIO 5F.0.LRG.31 - $3^{\circ}$ Of. de Notas (RJ), LRG n 31, f. 42.

${ }^{25}$ ANRJ, BR RJANRIO 5E.0.LRG.92 - 2 Of. de Notas (RJ), LRG n 92, f. 36.

${ }^{26}$ Aderir à escravidão brasileira não foi privilégio de franceses. Ingleses também o fizeram, o que
} 
Brasil, desenvolveram, de modo heterogêneo, estratégias no sistema de relações em que se encontravam. No tocante aos escravos, não só as diferenças entre africanos recém-chegados e brasileiros (REIS; SILVA, 1989, p. 20), mas também as próprias diferenciações internas à África reverberavam nas formas por meio das quais cativos alcançaram a liberdade (FLORENTINO, 2005, p. 353). Nesse sentido, é possível se questionar acerca de em que medida o senhor estrangeiro, perante escravo igualmente estrangeiro, pode ter encontrado disposições peculiares para a negociação da liberdade.

Escravos de nação Mina, ${ }^{27}$ por exemplo, puderam pagar por sua própria liberdade a senhores de origem estrangeira, incluindo franceses. Eduardo, em 1853, comprou sua liberdade por "um conto e duzentos mil reis" a Amedée Carmelle. ${ }^{28}$ Esse também foi o caso de José, que pagou 650 mil réis para ser alforriado por Catherina Liesse des Champs, em $1840 .{ }^{29} \mathrm{O}$ tino para o mercado da liberdade foi ainda mais evidente na negociação envolvendo essa mesma senhora e Francisco. No registro realizado em setembro de 1844, Catherina des Champs se apresenta como "senhora, e legítima possuidora de um escravo de nome Francisco de nação Mina”, frisando que ele não tinha "penhora nem hipoteca judicial" porque "do mesmo escravo, recebi outro de nome Manoel da mesma Nação, para o libertar de cativeiro". Logo, em função de uma troca, a senhora registrou que "por isso do preto Manoel Mina lhe dou quitação e na pessoa do dito Francisco Mina, transfiro a posse e senhorio direito e ação que

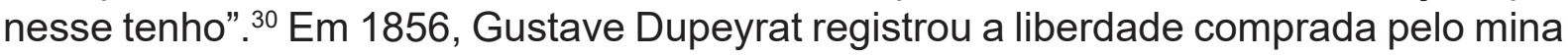
Manoel, que pagara um conto e quinhentos mil reis para obter sua alforria. ${ }^{31}$

O que esses casos denotam é a possibilidade de transformações de alteridades entre estrangeiros em busca de novas raízes: africanos acionando condições de negociações no Brasil escravista, e europeus oriundos de um centro de cultura liberal exercendo nesse Brasil o potencial das contradições de tal cultura.

\section{CONSIDERAÇÕES FINAIS}

A força da escravidão brasileira atraiu estrangeiros, fossem viajantes ou imigrantes. Diversas nacionalidades desempenharam papéis nesse palco, mas os casos franceses guardam um potencial específico de tensão em função da cultura liberal que se articulava em território francês ao longo do século XIX.

$\mathrm{Na}$ França, essa cultura atravessava espectros políticos variados. Uma disposição liberal incutiria mesmo em muitos conservadores o respeito por seus princípios. Não à toa, ao longo da primeira metade do século XIX, François Guizot,

\footnotetext{
permitiu inclusive críticas francesas. Como ressaltou Santos (2013, p. 142), a "luta contra o tráfico era interpretada como uma desculpa da Inglaterra para impor os seus interesses econômicos, mesmo porque muitos ingleses residentes no Brasil não abriam mão da posse de escravos". Para estudos de caso de senhores ingleses no Brasil, ver Guimarães (2015) e Ramos (2016).

${ }^{27}$ Cabe sublinhar diferenciações no tocante ao termo "mina", tal como ressaltado por Sidney Chalhoub (2012, p. 303) com base em análise de João José Reis, ressaltando que, no Rio de Janeiro, "o termo era mais abrangente, referindo-se aos negros oriundos da África Ocidental".

${ }^{28}$ ANRJ, BR RJANRIO 5E.0.LRG.85 - 2० Of. de Notas (RJ), LRG n 85, f. 260.

${ }^{29}$ ANRJ, BR RJANRIO 5E.0.LRG.70 - $2^{\circ}$ Of. de Notas (RJ), LRG n 70, f. 159.

${ }^{30}$ ANRJ, BR RJANRIO 5E.0.LRG.75 - $2^{\circ}$ Of. de Notas (RJ), LRG n 75, f. 311.

${ }^{31}$ ANRJ, BR RJANRIO 5F.0.LRG.14 - 3० Of. de Notas (RJ), LRG n 14, f. 57.
} 
cético quanto ao liberalismo da época das Luzes - a ponto mesmo de afirmar que muito se teria desaprendido no século XVIII -, tornar-se-ia emblemático ao vincular o princípio da capacidade política à participação na economia das "classes médias", tidas como "verdadeira aristocracia" por existirem "independentemente do poder" (ROSANVALLON, 1985, p. 113). Exercer a liberdade seria a condição para ser civilizado, e o trabalho livre se tornaria cada vez mais institucionalizado no Estado francês mediante estratégias para expurgar persistências do jacobinismo (ROSANVALLON, 2004) e a reiteração de um ideal meritocrático (CHARLE, 1991).

Não surpreende que tais formulações se tenham entremeado a desafios da abolição. Em um quadro global de culturas liberais, formulações como as de Guizot circularam em sintonia com aquelas que, tanto na França como no império britânico, terminariam por abordar o problema das relações entre colonialismo e escravidão por meio da premissa de que "era o Estado, não a lei da natureza, que tinha de conduzir os ex-escravos rumo ao progresso e à civilização" (COOPER et al., 2005, p. 71). Contudo, perante "uma contradição aparente entre o autocontrole e a autonomia envolvidos no liberalismo econômico e o desapossamento obviamente seletivo inerente à constituição da esfera política" (HOLT, 2005, p. 103), a contrapartida dessa liberdade inventada foi, muitas vezes, a reiteração de hierarquias raciais no interior da liberdade clamada enquanto faculdade humana, tal como na citação de Castelnau que iniciou este ensaio.

No Brasil, a escravidão guardou sua força, a despeito de transformações jurídicas (CHALHOUB, 2012; MAMIGONIAN, 2017), incorporando e fazendo incorporar disposições distintas daquelas que condicionaram, por exemplo, a trajetória haitiana. A ambiguidade de uma ordem política com valores liberais se manifestaria em outros sentidos. Assim, um francês, para se estabelecer no Brasil, poderia realizar o sonho de colonos derrotados no Haiti, sedimentando sua posição por meio da escravidão e encarnando um éthos cindido pelo Atlântico: se, para estabelecer-se no Brasil, diferenciar-se-ia do conterrâneo europeu, por outro lado, aproximar-seia do compatriota outrora estabelecido nas ilhas escravistas da pregressa América francesa, nas quais se "opunha um número reduzido de colonos a uma população de escravos forte e cada vez maior" (PÉTRÉ-GRENOUILLEAU, 2009, p. 49). Ao manter, de outro lado do Atlântico, a possibilidade do privilégio de depender de escravos, o Brasil oferecia a possibilidade de reprodução de um éthos aristocrático.

As alforrias concedidas por franceses não denotam apreço a um ideal de liberdade, mas sim a inserção eficaz "em uma sociedade que alforriava como nunca se viu em outras partes das Américas" (FLORENTINO, 2005, p. 333), ainda que, nela, processos de reescravização não tenham sido exceção (PINHEIRO, 2018, p. 114-115). Buscar nessas alforrias uma clivagem que reifique origens nacionais, tal como feito em teses acerca da hoje intitulada literatura de viagem (DAHER, 2007, p. 161), culminaria em alteridades reificadas, tais quais as emuladas em relatos de viagem. Não houve predisposição francesa à liberdade, tampouco um "olhar francês". É no trânsito de alteridades em movimento que os significados relacionais de "liberdade" podem ser elucidados, sobretudo caso se tenha em vista que esses significados "devem ser buscados em toda uma sequência de contextos históricos e sociais específicos" (COOPER et al., 2005, p. 52). Ainda que um retorno à França transformasse a territorialidade das identidades em questão, senhor e escravo, ao se valerem da alforria, não só deixavam para trás identidades pregressas, como também garantiam que o Brasil permanecesse como era antes de aqui chegarem: uma terra 
outra, tanto para africanos como para europeus, na qual ambos se convertiam a um escravismo peculiar. $\mathrm{O}$ lastro dos papéis sociais que exerceram far-se-ia valer, e as alforrias resguardavam sua "importância para a reprodução do status quo", permitindo que se alcançasse uma "liberdade conservadora pugnada pelo próprio sistema" (FLORENTINO, 2005, p. 356).

A cultura liberal francesa permanece, enfim, um território a ser explorado, não porque francesa, mas simplesmente porque liberal. Isso porque, da mesma forma que seria "um erro considerar o pensamento do lluminismo, a economia de mercado ou a teoria política liberal como um conjunto claro de princípios traído pela hipocrisia do colonialismo europeu", também seria equivocado neles reconhecer apenas "uma imposição totalitária de ideias políticas europeias ao resto do mundo em nome da universalidade" (COOPER et al., 2005, p. 57). Afinal, mesmo no interior da própria França essa cultura encontrou desafios. Cabe lembrar que o trabalho doméstico suscitara diferentes reações em meio aos homens de 1789, na medida em que a revolução, em momentos mais radicais, enxergou domésticos como mera extensão de seus senhores e, portanto, igualmente merecedores de degredo ou extermínio (PÉTRÉ-GRENOUILLEAU, 2009, p. 51-52). Além disso, não alcançara o próprio Voltaire - entusiasta do potencial civilizador do comércio e, para Victor Hugo, a síntese do espírito francês - considerável parte de sua distinção por meio de especulações financeiras (ORIEUX, 1966, p. 138-139) que terminaram por apoiar o tráfico de escravos? Como toda identidade, uma alteridade francesa liberal perante a escravidão se assentou sobre bases tensas e relacionais, mesmo quando emulada enquanto alteridade radical. Uma alteridade radical que, ainda que mudasse ao se radicar, talvez o fizesse justamente para jamais se erradicar. Talvez tenha residido nesse aspecto, inclusive, o que houvesse de caracteristicamente mais francês, no tocante a uma identidade moderna baseada em distinção e individualidade. Lançar luz sobre esses movimentos e os significados relacionais de "escravidão" e "liberdade" é permitir que usos de uma lógica universalista e moderna sejam articulados sem o estímulo a suas contradições. É permitir que haja Voltaire sem escravidão.

\section{REFERÊNCIAS}

ALMANAK LAEMMERT. Almanak administrativo mercantil e industrial do Rio de Janeiro para o anno bissexto de 1844. Primeiro Anno. Rio de Janeiro: Typographia Laemmert, 1843.

ALMANAK LAEMMERT. Almanak administrativo mercantil e industrial do Rio de Janeiro para o anno de 1845. Segundo Anno. Rio de Janeiro: Typographia Laemmert, 1844.

ALMANAK LAEMMERT. Almanak administrativo mercantil e industrial do Rio de Janeiro para o anno de 1855. Duodecimo anno. Rio de Janeiro: Typographia Laemmert, 1855.

ARAUJO, Ana Lucia. Romantismo tropical: um pintor francês no Brasil. São Paulo: Editora da Universidade de São Paulo, 2017. 
BLACKBURN, Robin. The Overthrow of Colonial Slavery, 1776-1848. London; New York: Verso, 2011 [1988].

BRIÈRE, Jean-François. Haïti et la France, 1804-1848: le rêve brisé. Paris: Karthala, 2008.

CANELAS, Letícia Gregório. "Eles não são livres, e eles não têm senhores; eles não são escravos, e eles não são cidadãos": liberdade precária e clandestina no Caribe francês (Martinica, século XIX). In: FREIRE, Jonis; SECRETO, María Verónica (org.). Formas de liberdade: gratidão, condicionalidade e incertezas no mundo escravista nas Américas. 1. ed. Rio de Janeiro: Mauad X; FAPERJ, 2018. p. 43-70.

CASTELNAU, Francis de. Expédition dans les parties centrales de l'Amérique du Sud, de Rio de Janeiro à Lima, et de Lima au Pará, exécutée par ordre du gouvernement français pendant les années 1843 à 1847. Histoire du Voyage. Paris:

P. Bertrand, 1850. Tome Premier.

CHALHOUB, Sidney. A força da escravidão: ilegalidade e costume no Brasil oitocentista. São Paulo: Companhia das Letras, 2012.

CHARLE, Christophe. Histoire sociale de la France au XIXe siècle. Paris: Seuil, 1991.

COOPER, Frederick; HOLT, Thomas C.; SCOTT, Rebecca J. Introdução. In: COOPER, Frederick, HOLT, Thomas C.; SCOTT, Rebecca J. Além da escravidão: investigações sobre raça, trabalho e cidadania em sociedades pós-emancipação. Trad. Maria Beatriz de Medina. Rio de Janeiro: Civilização Brasileira, 2005. p. 39-88.

DABADIE, F. À travers l'Amérique du Sud. Deuxième édition. Paris: Ferdinand Sartorius, 1859.

DAHER, Andrea. O Brasil francês: as singularidades da França Equinocial, 16121615. Rio de Janeiro: Civilização Brasileira, 2007.

DAVIS, David Brion. O problema da escravidão na cultura ocidental. Rio de Janeiro: Civilização Brasileira, 2001 [1966].

ELIAS, Norbert. Uma digressão sobre o nacionalismo. In: ELIAS, Norbert. Os alemães: a luta pelo poder e a evolução do habitus nos séculos XIX e XX. Rio de Janeiro: J. Zahar, 1997. p. 117-158.

ELIAS, Norbert. Os estabelecidos e os outsiders: sociologia das relações de poder a partir de uma pequena comunidade. Rio de Janeiro: J. Zahar, 2000.

FLORENTINO, Manolo. Sobre minas, crioulos e liberdade costumeira no Rio de Janeiro, 1789-1871. In: FLORENTINO, Manolo (org.). Tráfico, cativeiro e liberdade: Rio de Janeiro, séculos XVII-XIX. Rio de Janeiro: Civilização Brasileira, 2005. p. 331-366. 
FRANÇA, Jean Marcel Carvalho. Viajantes estrangeiros no Rio de Janeiro joanino: antologia de textos (1809-1818). Rio de Janeiro: José Olympio, 2013.

FREYCINET, Louis de. Voyage autour du monde exécuté sur les corvettes de S.M. “I'Uranie" et "la Physicienne" pendant les années 1817-1818, 1819 et 1820. Paris:

Pillet Ainé, 1825. Tome I. Disponível em: http://gallica.bnf.fr/ark:/12148/bpt6k99353d. Acesso em: 21 out. 2018.

GAIN, André. De la Lorraine au Brésil. Nancy: Société d'Impressions Typographiques, 1930.

GANNIER, Odile. La littérature de voyage. Paris: Ellipses, 2001.

GRENOUILLEAU, Olivier. Quando les Européens découvraient l'Afrique intérieure: Afrique occidentale, vers 1795-1830. Paris: Tallandier, 2017.

GÓES, José Roberto. São muitas as moradas. Desigualdades e hierarquia entre os escravos. In: FLORENTINO, Manolo; MACHADO, Cacilda (org.). Ensaios sobre a escravidão (I). Belo Horizonte: Editora UFMG, 2003. p. 201-216.

GONÇALVES, Andréa Lisly. As margens da liberdade: estudo sobre a prática de alforrias em Minas colonial e provincial. Belo Horizonte: Fino Traço, 2011.

GUIMARÃES, Carlos Gabriel. A presença inglesa no império brasileiro: a firma Edward Johnson \& Co. e o comércio exportador, 1842-1852. Tempo, Niterói, v. 21, n. 37, p. 187-207, 2015. Disponível em: http://www.scielo.br/pdf/tem/v21n37/14137704-tem-TEM_1980_542X2015v213705.pdf. Acesso em: 21 out. 2019.

HOLT, Thomas C. A essência do contrato: a articulação entre raça, gênero sexual e economia política no programa britânico de emancipação, 1838-1866. In: COOPER, Frederick; HOLT, Thomas C.; SCOTT, Rebecca J. Além da escravidão: investigações sobre raça, trabalho e cidadania em sociedades pós-emancipação. Trad. Maria Beatriz de Medina. Rio de Janeiro: Civilização Brasileira, 2005. p. 91-129.

KURY, Lorelai. Histoire naturelle et voyages scientifiques. Paris: L'Harmattan, 2001.

LEITE, Ilka Boaventura. Antropologia da viagem: escravos e libertos em Minas Gerais no século XIX. Belo Horizonte: Editora UFMG, 1996.

MAMIGONIAN, Beatriz G. Africanos livres: a abolição do tráfico de escravos no Brasil. 1. ed. São Paulo: Companhia das Letras, 2017.

MATTOSO, Kátia M. de Queirós. Ser escravo no Brasil. 3. ed. São Paulo: Brasiliense, 1990.

MEILLASSOUX, Claude. Préface: de classe et de couleur. In: GAUTHIER, Florence (dir.). Périssent les colonies plutôt qu'un principe!: contribution à l'histoire de 
l'abolition de l'esclavage, 1789-1804. Paris: Société des études robespierristes, 2002. p. 5-10.

MEILLASSOUX, Claude. Antropologia da escravidão: o ventre de ferro e dinheiro. Trad. Lucy Magalhães. Rio de Janeiro: J. Zahar, 1995.

MELLO, Maria Elizabeth Chaves de (org.). Um francês nos trópicos: Francis de Castelnau: o olhar de um viajante no século XIX. Rio de Janeiro: 7Letras, 2015.

ORIEUX, Jean. Voltaire, ou la royauté de l'esprit. Paris: Flammarion, 1966.

PÉTRÉ-GRENOUILLEAU, Olivier. A história da escravidão. Trad. Mariana Echalar. São Paulo: Boitempo, 2009.

PINHEIRO, Fernanda Domingos. Em defesa da liberdade: libertos, coartados e livres de cor nos tribunais do Antigo Regime português (Mariana e Lisboa, 1720-1819). Belo Horizonte: Fino Traço, 2018.

PIOLLET, Sophie; PIQUIONNE, Nathalie; ROUX, Delphine. Milscent créole historien de la Révolution de Saint-Domingue, 1790-1794. In: GAUTHIER, Florence (dir.). Périssent les colonies plutôt qu'un principe!: contribution à l'histoire de l'abolition de l'esclavage, 1789-1804. Paris: Société des études robespierristes, 2002. p. 23-42.

POTELET, Jeanine. Le Brésil vu par les voyageurs et les marins français 1816-1840: témoignages et images. Paris: L'Harmattan, 1993.

RAMOS, Pedro Brandão de Sousa Culmant. Homens de confiança: moral, antiescravismo e o abolicionismo inglês na supressão do tráfico brasileiro de escravos (1836-1846). 2016. 128 f. Dissertação (Mestrado em História Social) Instituto de História, Universidade Federal do Rio de Janeiro, Rio de Janeiro, 2016.

READ, Ian. The hierarchies of Slavery in Santos, Brazil, 1822-1888. Stanford: Stanford Univ. Press, 2012.

REIS, João José; SILVA, Eduardo. Negociação e conflito: a resistência negra no Brasil escravista. São Paulo: Companhia das Letras, 1989.

ROSANVALLON, Pierre. Le modèle politique français: la société civile contre le jacobinisme de 1789 à nos jours. Paris: Seuil, 2004.

ROSANVALLON, Pierre. Le moment Guizot. Paris: Gallimard, 1985.

ROSSATO, Luciana. A lupa e o diário: história natural, viagens científicas e relatos sobre a capitania de Santa Catarina (1763-1822). Itajaí: Universidade do Vale do Itajaí, 2007. 
SANCHES, Vanessa Gomes Ramos. Pelos caminhos da liberdade: alforrias no Rio de Janeiro imperial (1840-1888). 2017. 263 f. Tese (Doutorado em História Social) Instituto de História, Universidade Federal do Rio de Janeiro, Rio de Janeiro, 2017.

SANTOS, Cláudia. Narrativas de viagem e escrita da história: os franceses no processo abolicionista brasileiro (1850-1899). Rio de Janeiro: 7Letras, 2013.

SECRETO, María Verónica. Soltando-se das mãos: liberdades dos escravos na América espanhola. In: AZEVEDO, Cecília; RAMINELLI, Ronald (org.). História das Américas: novas perspectivas. Rio de Janeiro: FGV, 2011. p. 135-159.

SÜSSEKIND, Flora. O Brasil não é longe daqui: o narrador, a viagem. São Paulo: Companhia das Letras, 1990.

TODOROV, Tzvetan. Nous et les autres: la réflexion française sur la diversité humaine. Paris: Seuil, 1989.

TOUSSAINT-SAMSON, Adèle. Uma parisiense no Brasil. Trad. Maria Lucia Machado. Rio de Janeiro: Editora Capivara, 2003 [1883].

\title{
NOTAS
}

\author{
AUTORIA \\ Daniel Dutra Coelho Braga: Doutor. Pesquisador autônomo, Florianópolis, SC, Brasil. \\ ENDEREÇO PARA CORRESPONDÊNCIA \\ Rua Afonso Luiz Borba, 129, 8806-2040, Florianópolis, SC, Brasil.
}

\section{AGRADECIMENTOS}

Este artigo é o desdobramento de projeto de doutorado primordialmente dedicado a analisar expedições científicas francesas na América do Sul. Agradeço ao prof. dr. Manolo Florentino por ter gentilmente compartilhado entradas de banco de dados que permitiram identificar alguns dos atores mencionados no texto. A interpretação dos dados averiguados em livros de registro geral, todavia, é de minha inteira responsabilidade.

\section{FINANCIAMENTO}

Este artigo foi financiado com bolsa de doutorado da Coordenação de Aperfeiçoamento de Pessoal de Nível Superior (CAPES).

\section{APROVAÇÃO DE COMITÊ DE ÉTICA EM PESQUISA \\ Não se aplica.}

\section{CONFLITO DE INTERESSES}

Não houve conflito de interesses.

\section{LICENÇA DE USO}

Este artigo está licenciado sob a Licença Creative Commons CC-BY. Com essa licença você pode compartilhar, adaptar e criar para qualquer fim, desde que atribua a autoria da obra. 


\section{PUBLISHER}

Universidade Federal de Santa Catarina. Programa de Pós-Graduação em História. Portal de Periódicos UFSC. As ideias expressadas neste artigo são de responsabilidade de seus autores, não representando, necessariamente, a opinião dos editores ou da universidade.

\section{EDITORES}

Flávia Florentino Varella (Editora-chefe)

Tiago Kramer de Oliveira

Waldomiro Lourenço da Silva Júnior

\section{HISTÓRICO}

Recebido em: 26 de abril de 2019

Aprovado em: 28 de outubro de 2019

Como citar: BRAGA, Daniel Dutra Coelho. Da radical à radicada: alteridades entre franceses e escravos no Rio de Janeiro oitocentista. Esboços, Florianópolis, v. 27, n. 44, p. 94-114, jan./abr. 2020. 